\title{
22 Chinese Horse Medicine: Texts and Illustrations
}

\author{
Paul D. Buell, Timothy May and David Ramey*
}

The domesticated horse appeared early in China. It was used to draw chariots no later than Shang times (late 2nd millennium), and for riding during the mid-Zhou (after the 6th century BCE), in imitation of China's pastoral enemies, then pressing upon the Middle Kingdom. ${ }^{1}$ Nonetheless, in spite of its importance for maintaining mounted armies and other uses of the horse, China was late to develop a specialised horse medicine. Veterinarians are among those medical officials mentioned in the Zhouli 周禮 (Rituals of the Zhou). This is a work of early Han 漢 times. ${ }^{2}$ There are also hints of specialised knowledge of horses in other sources (e.g., the Bo Le 伯 樂 tradition found in the Zhuangzi 莊子), ${ }^{3}$ but there are no actual texts until much later. The most important Chinese works date only from the Ming 明 dynasty (1368-1644).

\section{Texts}

The earliest surviving veterinary texts of any sort in China are a few stray horse recipes found among Dunhuang 敦煌 documents. These are largely from Qin 秦 $\left(255^{-206}\right.$ BCE $)$ and Han 漢 (206 BCE-220 CE) times. ${ }^{4}$ In them, treatment is overwhelmingly herbal. This parallels the main focus of Chinese medicine for humans down to the present. Later, the popular sixth-century manual Qimin yaoshu 齊民要 術 (Essential Arts to Assist the People) (hereafter QMYs), included its own selection of veterinary recipes. ${ }^{5}$ They were not just for horses, but for a variety of other animals as well.

In these early texts, clear development is evident. The QMYs, for example, calls not just for herbal treatment but also for a specialised bleeding and cauterisation. This is a first for Chinese veterinary medicine although not, apparently, for humans. ${ }^{6}$ Be that as it may, bleeding and

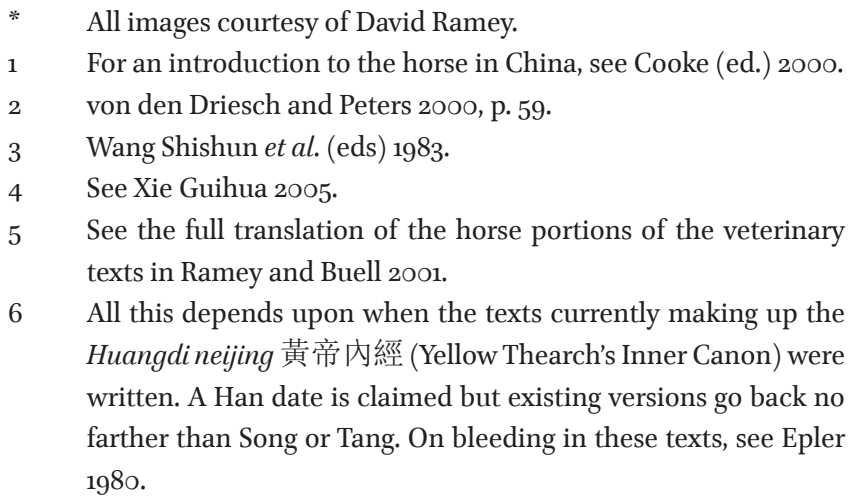

$6 \quad$ All this depends upon when the texts currently making up the Huangdineijing 黃帝內經 (Yellow Thearch's Inner Canon) were written. A Han date is claimed but existing versions go back no farther than Song or Tang. On bleeding in these texts, see Epler 1980.

cauterisation are clearly not treatments of choice in the QMYs. These remained herbal. Already the QMYS shows the influence of the theoretical system developed earlier for human patients, including the key concept of Qi 氣, the resident Yang 陽 energy and motive force pervading the body according to the Chinese medical system, although references to Qi remain a very minor tradition in the QMYS.

The QMYs was written during the Toba Wei 魏 dynasty (386-535), a period not only of foreign rule in China, but also of great foreign influence, especially through the medium of Buddhism. This may be the source of some of the new ideas in the QMYS. Its bleeding and cauterisation, for example, are differently applied compared to what we know of the human medicine of the time. ${ }^{7}$ In fact the closest equivalents of the bleeding and cauterisation of the QMYS must be sought in Greece and Rome, where such treatments had a far longer history than in China. ${ }^{8}$

Shortly after the time of the QMYS (early 6th century), references to specialised veterinary texts begin to appear in our sources. Several are mentioned in early bibliographies, including that accompanying the Suishu 隋書, the official history of the Sui 隋 dynasty (58o-618). It was written in Tang 唐 times. Unfortunately, none of these early texts appear to have survived, except perhaps as fragments in later documents. ${ }^{9}$ Veterinary information does continue to occur in passing in other sources that do survive, including a Northern Song 宋 (96o-1125) military manual, ${ }^{10}$ but information in them is limited. A Northern Song date is claimed for a treatise on camel medicine, but this text only survives in a late, extensively edited form, ${ }^{11}$ and as such is an unreliable guide to Song practice. By contrast, a late 14th-century compilation does contain genuine works from earlier times. This is the Simu anji ji 司牧安䮑集 (Collections for Pacifying Stallions when Administering Flocks) (hereafter SMAJJ), published in 1384. Judging from internal evidence, most of its components are apparently

The cauterisation called for in Qimin yaoshu recipes, for example, had little or nothing to do with moxa-cautery, the indigenous tradition of cauterisation already established in China. It seems to represent something entirely novel, and probably an introduction from somewhere else.

$8 \quad$ See Buell, May and Ramey 2010.

9 See the discussion in Zhou Jiezheng 196o.

10 See von den Driesch and Peters 2003, p. 6o.

11 Discussion in Franke 1997. We do not share Franke's views on the early dating of this text. 
from the 11th and 12th centuries, but some may be later. In particular, some show the signs of the developed correspondence theory that first came to fruition in human medicine during late Song, Jin 金 (1125-1234) and Yuan 元 (126o-1369) times. Most SMAJJ texts are probably northern in origin (China was disunited at the time) although some, probably those added last, may have been Southern Song $\left(1125^{-1279)} \cdot{ }^{12}\right.$

From roughly the same period comes a more significant work, the first surviving monograph devoted exclusively to horse medicine, the Xinbian jicheng mayifang 新編集 成馬醫方, (Newly Printed and Collected Recipes for Horse Medicine), which, although written in Chinese, is actually a Korean work. It was first published in $1399 .{ }^{13}$

Despite these important early efforts, the most significant works in the genera of horse medicine date only from the Ming 明 dynasty (1368-1644). Among them is the Yuan Heng liaoma ji 元亨療馬集 (Yuan and Heng's Collection for Treating Horses) (hereafter YHLMJ), first published under that title in 1608. The existing version is supposedly the work of two brothers, horse specialists with long experience. In fact, this is not likely to have been the case. As the Korean scholar Kang Myun Hee 姜冕熙 has shown, the YHLMJ is actually a new edition of an earlier text, the Liaoma ji 療馬集 (Collection for Treating Horses), now lost. It lacked any reference to two brothers Yuan and Heng. ${ }^{14}$ Although emphasised in the preface to the 1608 edition, this fraternal tradition is also suspect because the two characters Yuan 元 and Heng 亨 can also be taken as a reference to the Qian 乾 chapter of the Yijing 易經 (Book of Changes). ${ }^{15}$ In any case, the existing YHLMJ has clearly been compiled from a variety of existing sources. In this respect it is like the older SMAJJ, although editors have made the material in the YHLMJ fit more seamlessly than is the case with the heterogeneous material in the earlier collection.

Spurious attribution notwithstanding, the YHLMJ is an extraordinarily rich work. It is in six books and includes

12 For further analysis and discussion, see Buell, May and Ramey 2010 .

The text was later republished in China, in 1634, and subsequently in Japan, showing its popularity. The authors are given as Quan Zhonghe 權仲和 and Han Shangjing 韓尚敬 (reading their names in Chinese).

14 Kang Myun Hee 1988.

15 The Qian chapter, the first in the book, begins: Yuanheng li chen 元亨利真, 'the originating benefits the propitious'. In this case the 'originating' refers to the originating of the 10,0oo things, particularly those comprising part of the biological world. Despite the preface to the 1608 edition, it is unlikely that any literate Chinese would have failed to note the reference. detailed discussion of a variety of topics: horse physiognomy; horse whorl lore, a kind of divination based upon close examination of the configurations assumed by a horse's hair that is also found outside of China; ${ }^{16}$ horse diagnosis and physiology; horse pathology, including a consideration of the eye diseases of the horse; taboo and propitious days for treatment; correspondences; and a huge section, comprising all of books 3 and 4 , on specific conditions and the treatments preferred for them. At the end of the book, there is also a detailed listing of herbal medicines and preparations and their specific applications.

The Ming edition apparently became rare, the case today too, and in the 18th century, an entirely new edition was made of the YHLMJ. This edition is still in general use. Editions based on this new edition have continued to be made down to the present, each, as a rule, with changes to suit different times, making the use of the most modern editions of the text problematical at best. The 18th-century reworking was by Guo Huaixi 郭懷西 and was published in 1732 in his collection Xinke zhushi ma niu tuo jing daquan 新刻注釋馬牛駝經大全 (Newly Printed and Annotated Horse, Ox, and Camel Classics).

Another major horse text of the Ming period is the Xinke ma shu 新刻馬書, (Newly Printed Horse Book), from 1594. It is by the Ming literatus Yang Shiqiao 楊時喬 (d. 16o9), who is also the author of a treatise on Ming horse management, the Mazheng ji 馬政記 (Record of the Horse Administration). The latter work is mostly devoted to official pronouncements. This is not the case with Yang's 'Horse Book'. It is in 13 books and does not come down to us complete. The text is highly literary and is replete with quotations from classical sources and copies out whole documents in some cases. Topics discussed include physiognomy and general aspects of judging horses, general methods for treatment, correspondence theory (the fullest discussion of this in the traditional veterinary literature), physiology, pathology, diagnosis, and bleeding and cauterisation, with some consideration of specific pathologies. Book 12 is lost and book 13 is in fragments only; the latter deals with the treatment of donkeys. One chapter reproduces a treatise on 'difficult issues' already known from the SMAJJ. ${ }^{17}$ Throughout the book, where treatment is called for, the emphasis is herbal. Bleeding and cauterisation is more prominent than in the Korean Xinbian jicheng mayi fang of 1399, for example, possibly indicating that this form of treatment, which is also important in the YHLMJ, had gained in acceptance.

16 See, for example, von den Driesch and Peters 2003, p. 68.

17 This is the Zaofu bashiyi nanjing 造父八十一難經, (Father Zao's Classic of 81 Difficult Issues) in the form of poetic couplets. 


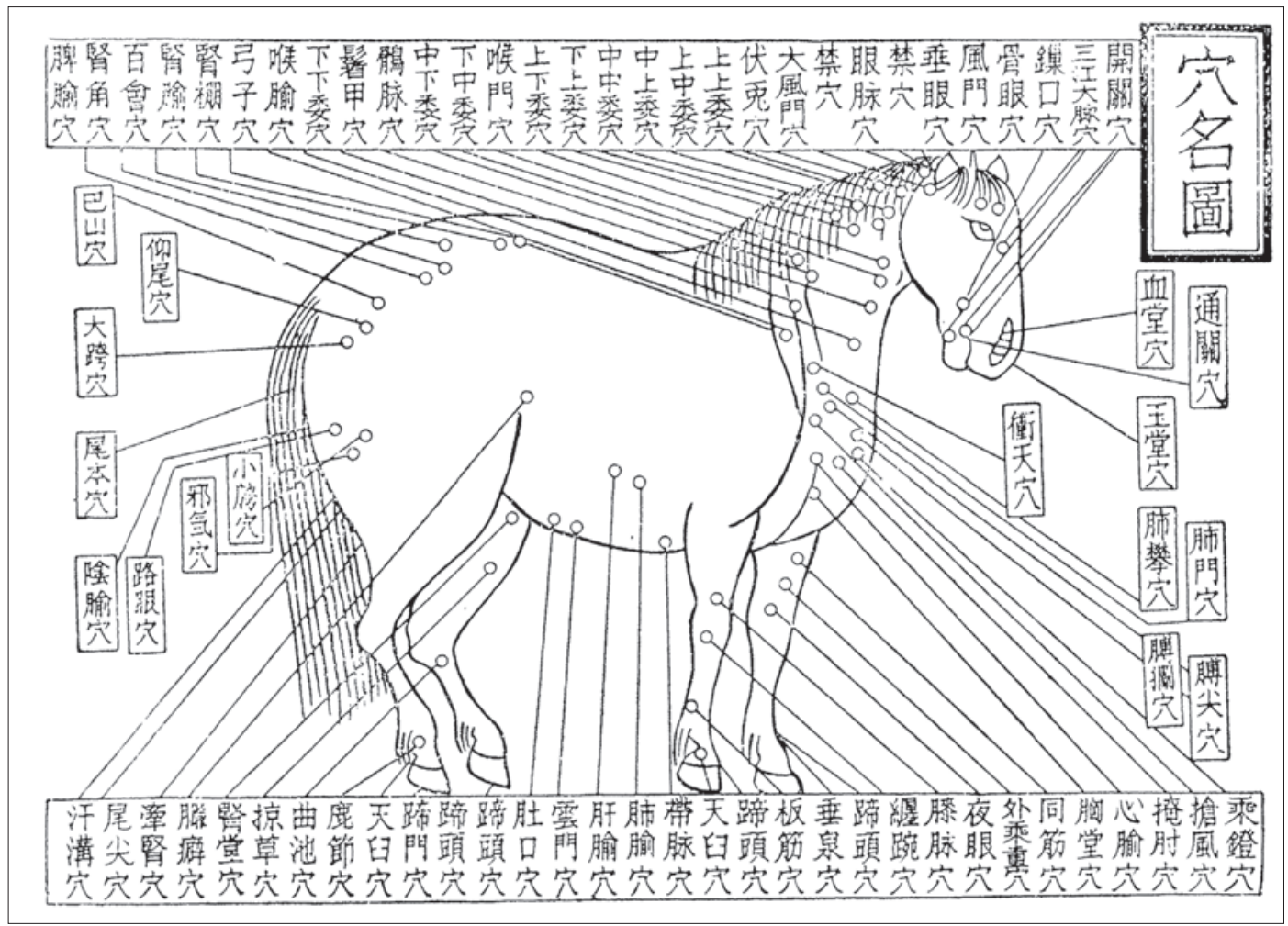

Figure 22.1 'Map of Indentations'. Source: SMAJJ, p. 28

These texts, including major revisions, as in the case of the YHLMJ, have set the tenor of Chinese horse medicine down to the present. Their style is also closely imitated by a rich manuscript tradition, including texts from various periods collected by David Ramey. In fact, little changed in China in the basic treatment of horses until the introduction of modern veterinary practices under the Nationalist and Communist regimes. This included, from the 196os, the first veterinary acupuncture with fine needles practised in China. This has since been taken up not only in China but throughout the world including the United States and Europe, where it has achieved some popularity. ${ }^{18}$

\section{Illustrations}

One major feature of the recent, printed tradition of Chinese veterinary medicine is that nearly all the texts, starting, in the case of horse medicine, with components of the sMAJJ, are illustrated, some very well illustrated. This is true of many of the major manuscripts as well, some in

18 Actually, as we will show in a separate paper, the use of acupuncture on animals appeared in Europe before it appeared in China, in the early 19th century and veterinary acupuncture, like human acupuncture, has been heavily influenced by French physicians and their ideas. the Ramey collection, for example. One is even beautifully illustrated in colour, although most sketches in them are black and white.

Typical of the printed tradition is the short Bo Le zhenjing 伯樂鍼經 (BLZJ) (Bole's Needling Classic), reproduced in the SMAJJ of 1384 , but which clearly circulated separately before that date, although how much before that date is uncertain. The current BLZJ, along with a parallel text, the Bo Le hualuo tu ge jue 伯樂畫烙圖歌訣（The Song Secrets of the Diagram of Bo Le's Branding) (BLHLTGJ), to be discussed next, are most likely works of the Yuan dynasty (126o-1368). Both texts appear to show Western influences, and the Mongol Yuan period was a maximal period for such influences in China, particularly those coming from the Islamic world, including its veterinary literature and methods of practice. ${ }^{19}$

In its present form, BLZJ is in two parts. Part One, and this may be the oldest component of the text, is a 'Map of Indentations' (xueming tu 穴名圖), here reproduced from a modern print of an 18th-century edition, the earliest available, showing 78 places on a horse. Each is named, for therapeutic intervention (Fig. 1).

19 See the detailed discussion with examples of the medical convergences involved in Buell, May and Ramey 2010. See also Buell 2008. 


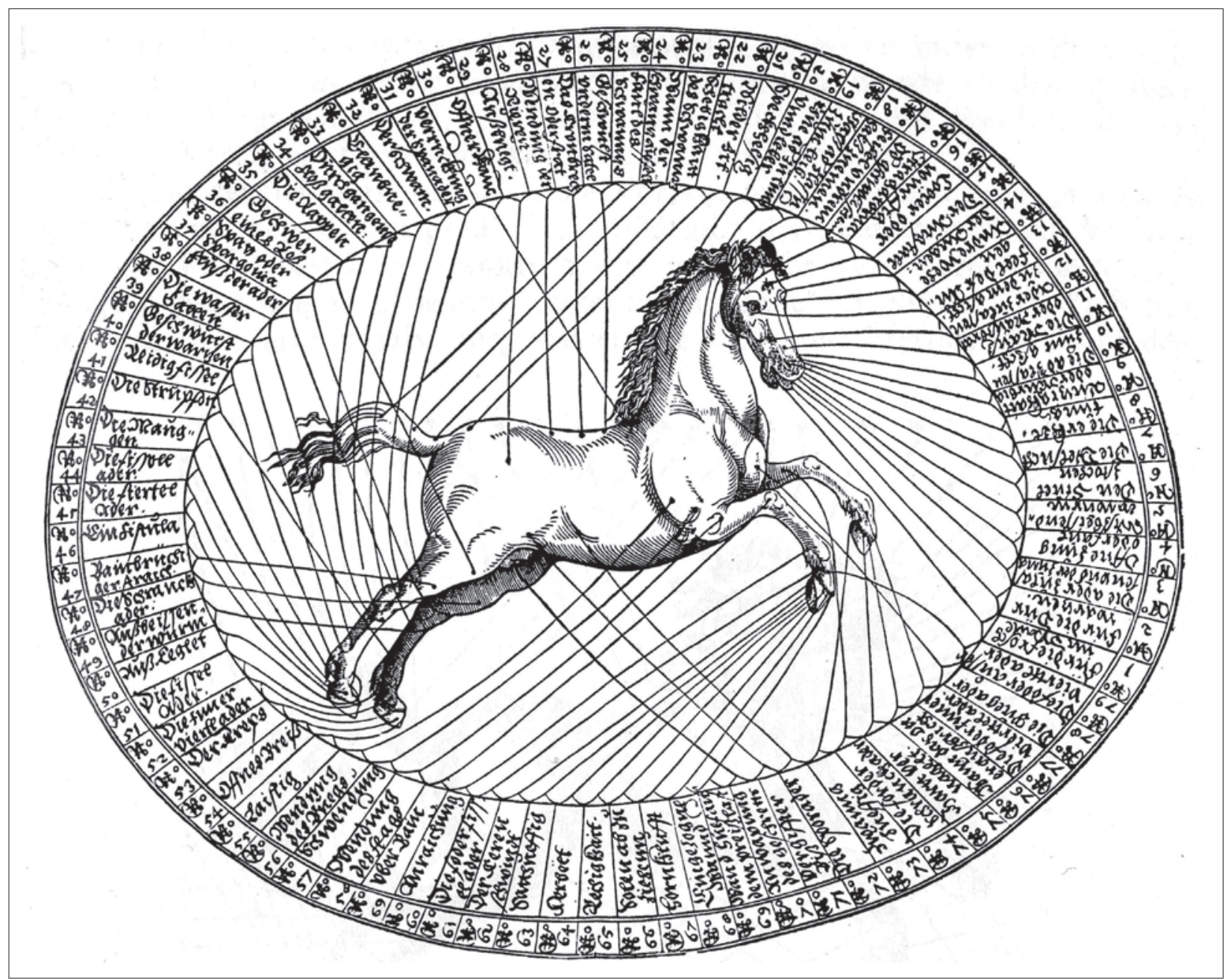

Figure 22.2 Figure from Künstlicher Bericht und allerzierlichste Beschreybung. Source: Stork 1971, p. 681

Part B is the BLZJ proper. The first part is a general theoretical consideration of 'needling'. The language is very much influenced by the theory of human acupuncture, although the actual interventions, which follow, have nothing whatever to do with it. ${ }^{20}$ Not one calls for

2O SMAJJ, pp. 29-34. The following are examples of the relevant sections. Numbers are the order that the discussions appear in the text:

[1.] Eye Pulse Indentation (Yanmo xue 眼脉穴): [This is] four fingers behind the eye. One needle 2 fen 分 [1oth of Chinese inch] deep at this indentation. Bleed. It cures liver and organ heat, eye swelling, and crying disease.

[18.] Liver Main Conduit Indentation (Ganchu xue 肝腧穴): [It is in] the left inside kernel bank [zuo lijenpan 左裡仁畔], the inside of rib number 5 from the rear, 1 chi 尺 [Chinese foot], 5 cun 寸 from the spine. One fire needles at this indentation 1 cun. It treats all diseases associated with the liver.

[21.] Great Wind Gate Indentations (Da fengmen xue 大風門 穴): [They are located] one finger behind the bases of the two ears. One cauterises at this indentation with a branding iron, and a round brand. The depth is 3 fen. One applies oil. It treats needling perse. All insertions are for purposes of bleeding, cauterisation ('hot needling'), branding, or to achieve minor surgery (using scalpels, 'white needles'), making the whole tradition, including points identified, quite parallel to equivalent material from the West. The West had its own diagrams of insertion points, nearly as old as those from China, and the Islamic World. ${ }^{21}$ Figure 2 shows a German example, based upon many earlier precedents reaching back to the Middle Ages. The close similarity of the 'map'

a sudden seizure, destroying wound wind, or various wind diseases.

[33.] Heart Main Conduit Indentation (Xinchu xue 心腧穴): [This is] on the breast bone. In the case of this indentation, if there is suffering from heart jaundice disease, one uses white needle [scalpel] barbs, 10 or more needles, to needle and produce yellow water and blood. Take a qian 錢 [Chinese ounce] of salt and rub into the needle wound. Draw out the yellow water and poison Qi. If there is no treatment, an ulcer will form that will penetrate to the heart and lung.

21 See the discussion and sample translations in Buell, May and Ramey 2010. 


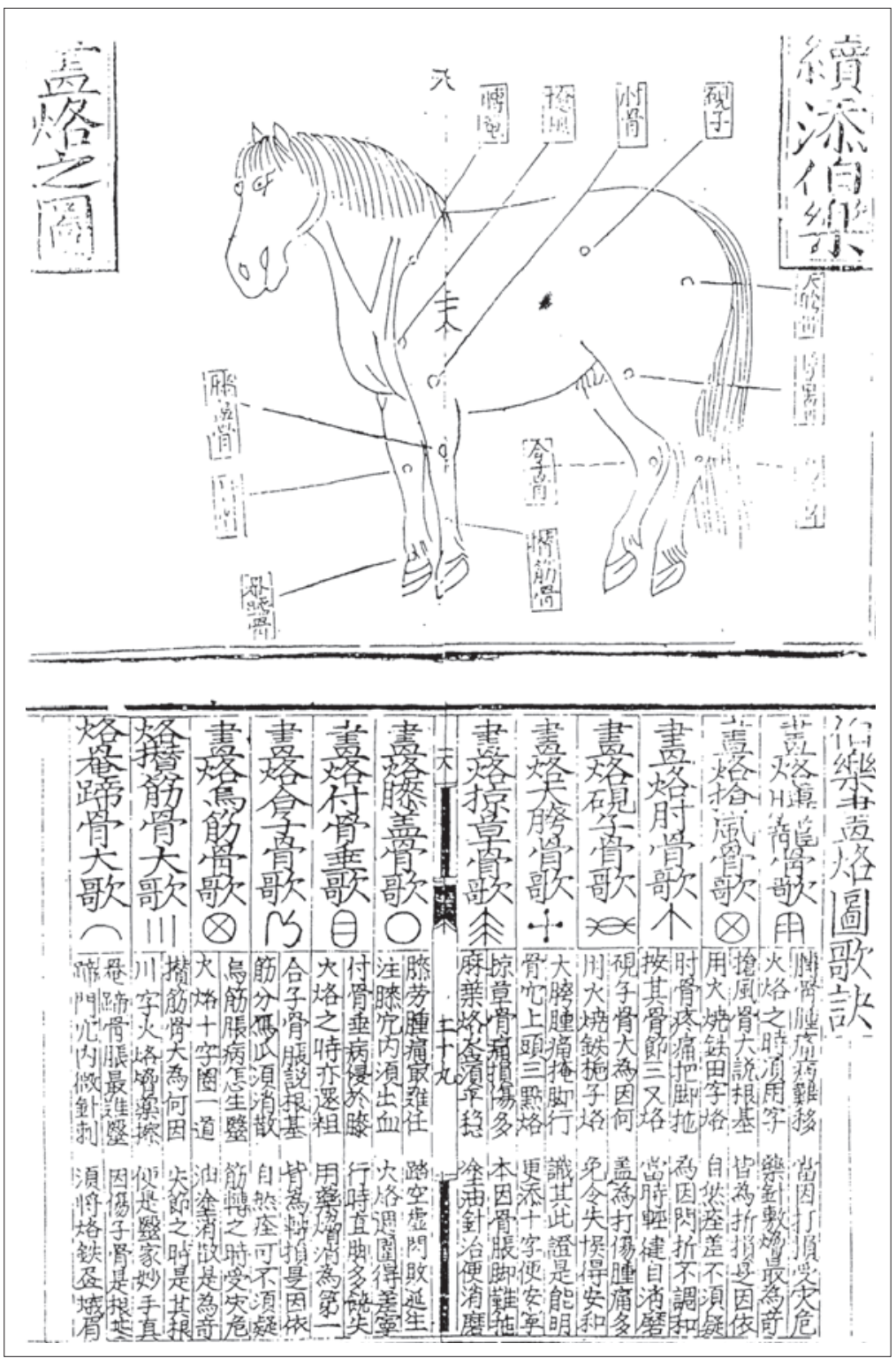

Figure 22.3 Bo Le Branding Diagram. Source: SMAJJ, pp. 48-9. See complete translation in Buell, May and Ramey 2010.

The 12 places in the top illustration are (from top, clockwise): 1. 'The ink stone'; 2. 'The foreleg bone'; 3. 'The adverse wind [bone]'; 4. 'The shoulder dragon [bone]'; 5. 'The kneecap bone'; 6. 'The transfer bone'; 7. 'The fish net hoof bone'; 8. 'The fathering sinew bone'; 9. 'The fox bone'; 10. 'The bird sinew bone'; 11. 'The seizing grass bone'; 12. 'The great thigh bone'.

Below, the first two items are: Song for branding the transfer bone. [forked three]: pain of the transfer bone makes the feet drag. There can be no harmonisation due to twisting breaking. If one brands a forked three at this bone joint, at that time the [feet] will be light and strong, and they will accurately sharpen [adjust] themselves; Song for branding the ink stone bone. [seal script character for $z h i$ 柧, 'gardenia nut']: The ink stone bone is very much a cause [of disease], and there is thus a great deal of swelling as a result of wounds from blows. One uses a fire branding iron and brands a zhi character. One will thereby avoid causing neglect, and one will be able to attain a proper arrangement.

shown in Figure 1 to this German illustration is striking. Both provide information on cauterisation and bleeding.

The BLHLTGJ is similar to the BLZJ, but showing fewer places on the body of a horse for actual intervention, in this case therapeutic branding. This is a special kind of cauterisation, either with specially shaped brands (the likely interpretation) or with 'fire irons' intended to write out and build up shapes. The purpose is to produce a brand at determined points responding to associated conditions. Interestingly, such branding was already well known in the European and Islamic West. Also interestingly, some of the symbols called for are quite similar to the Chinese: ${ }^{22}$

22 See Buell, May and Ramey 2010 for a detailed comparison with symbols from the horse book of Abu Bekr (Egypt, first half of the 14th century) 


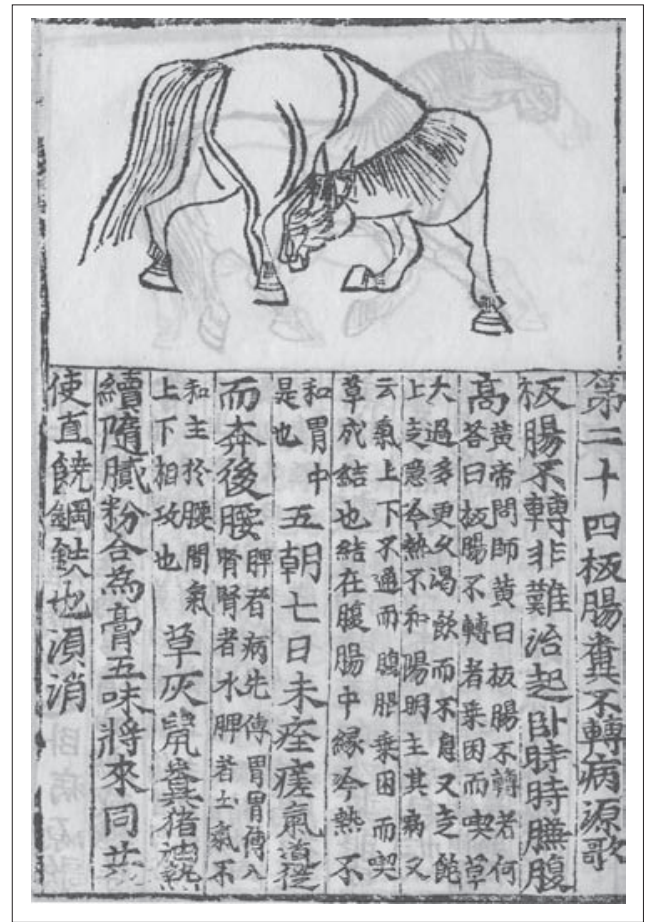

Figure 22.4 Colic from the Xinbian jicheng mayifang (56a). The text reads: Number 24: Disease origin [is] in a stiff intestine and excrement that does not move. The song: When there is a stiff intestine and excrement that does not move it is not difficult to treat. [The animal] lies down and gets up frequently. The spleen and belly are high. [Textual note in smaller characters:] (The Yellow Thearch asked [Ma] Shi Huang [馬] 師黃 [皇] [Horse-Master Huang?] saying: as for the condition where the intestine is stiff and the excrement does not move, what is it? He replied saying: when the intestine is stiff and the excrement does not move it is a matter of the horse eating grass excessively on account of difficulty, and there is a lot of excrement. It hardens for a long time. The horse drinks and does not rest. Also it sometimes eats to satiation and sometimes harbours chill and heat and this is not in accord with the brightness of the intestines. It is primarily this illness. It is also said: when the Qi 氣 goes up and down and does not go through, the belly swells. On account of difficulty [the horse] eats grass and [this] forms knots. Inside the intestines the knots are a reason for chill or heat. It does not accord with what is in the stomach. It is a matter of this.) If there is no improvement for five mornings and seven days, the Qi ways follow this and run to the rear loins. [Textual note:] (What is to be considered is that the illness first is transmitted to the stomach. The stomach transmits into the kidneys. The kidneys [are ruled by] water. What is to be considered is that the earth [?] Qi does not accord with what is dominant in the loins. The Qi goes up and down and mutually conflicts.) Take grass ash, rat dung, and pig oil [lard]. Heat [each] and in succession make an oily powder. Combine into an ointment. The five flavours [spices] will subsequently be combined [with it]. Make sure [the material] is abundant. A hard iron will also dissipate it.

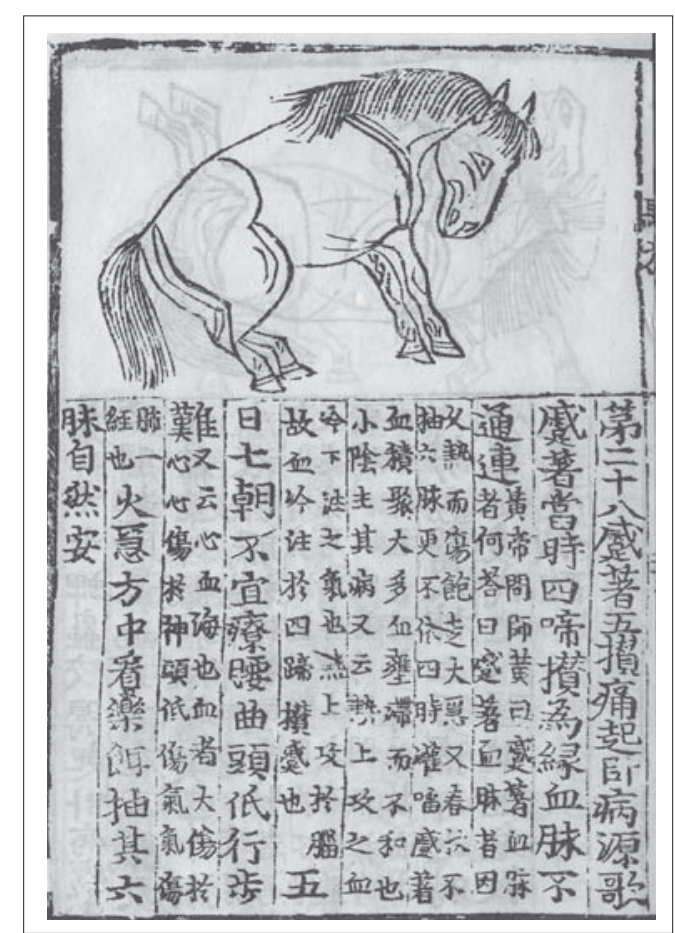

Figure 22.5 Hoof Problems from the Xinbian jicheng mayi fang (58a). The text states: Number 28: disease origin situated in cramping manifestations, and in five gathering pain when lying down and getting up. The song [says:] at the time of cramping manifestations, the four hooves [ $\mathrm{ti}$ 啼 $=$ 蹄] are gathered because of the fact that the blood pulse does not go through and is caught up. [Textual note:] (The Yellow Thearch asked [Ma] Shihuang saying: when there are cramping manifestations of the blood pulse what reply is there? Cramping manifestation blood pulse is because of long term heat and wounding and [because the horse] eats to repletion going beyond [what it should] to be greatly careful. Also spring and autumn, if there is at the time pulling of the six pulses, then they will then not accord with the four seasons and there is pouring and chewing and cramping manifestations. The blood gathers together. Most of the blood is obstructed and congeals and does not accord. A lesser Yin 陰 [condition] dominates the disease. It is also said that heat goes up and attacks. Blood and chill descend. This is puddle Qi. The blood goes up and attacks up into the brain, thus the blood is chilled and flows into the four hooves. This is gathering cramping.) If in five days and seven mornings there is no sign of healing, if the loins [of the horse] are crooked and the head is held low, and the gait and steps are difficult, then (also it says if the heart's blood is a sea. Blood is greatly wounded in the heart. The heart is harmed in the spirit. If the head is held down it is wounded Qi. The Qi wounds all the main arteries of the lung.) in the case of the herbs in the Fire Care Recipe, see that the medicinal cake draws out its six flavours. [The condition] will be calmed naturally. 
Although many of the early illustrations in the printed tradition are of this sort, self-contained, and probably separately circulated as independent publications, connected sets of illustrated texts also appear. These are the single largest component of illustrated material in the YHLMJ, for example.

Opposite are two examples (Figs 4 and 5) of the early illustrations from the Korean Xinbian jicheng mayi fang. The first shows a horse suffering from a form of colic. The illustration clearly shows the horse in a position typical of colic (non-specific pain originating from the abdomen), looking at its abdomen, and in obvious discomfort. The text identifies the condition, with help from a quotation mentioning the Yellow Thearch himself, an originator and patron saint in veterinary as well as human medicine. The clinical description, in terms of the lack of excrement, failure to rest, and persistent drinking, is accurate. It then provides treatment options. The second shows another unfortunate horse, this one suffering from a hoof problem (laminitis). Again, the illustration is remarkable, as it shows the horse unwilling to bear weight on its fore feet, as is typical of laminitis, a condition in which the connections

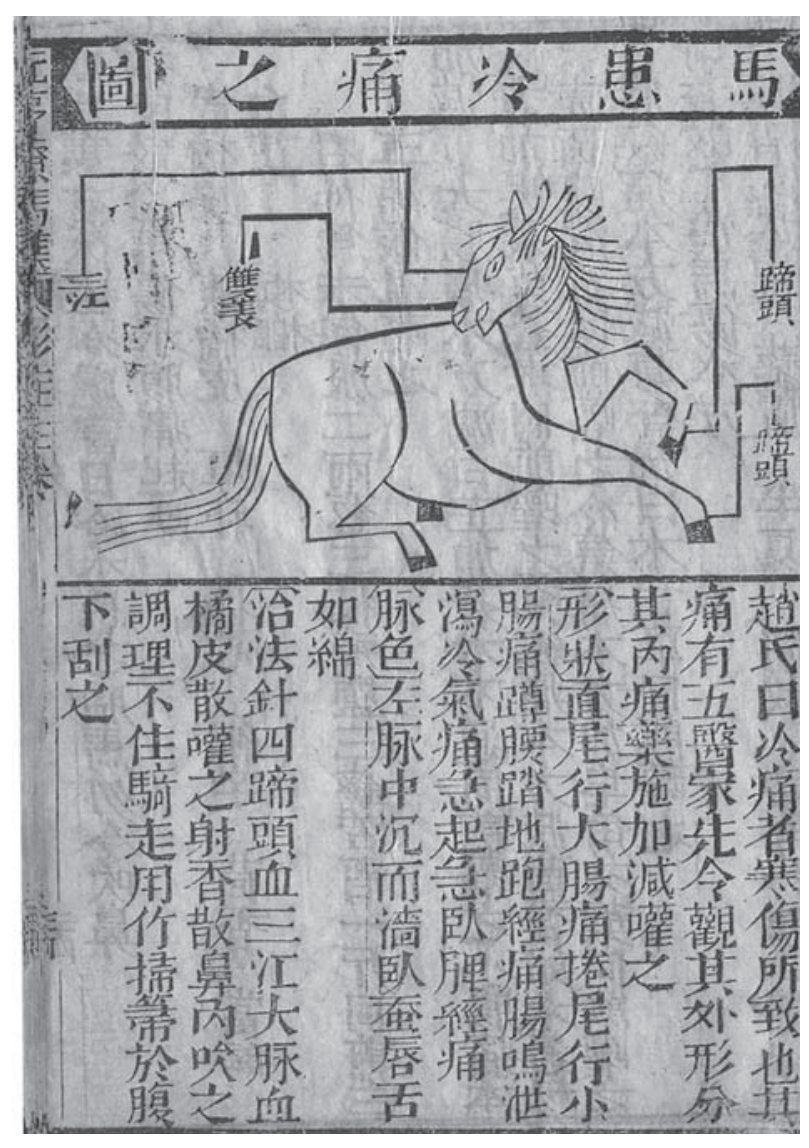

Figure 22.6 Horse suffering from Chill Pain (2) (continued) holding the hoof to the underlying structures are compromised, and which causes considerable pain. The format is the same, except that treatment is more generalised and the implication is that the horse will recover on its own if allowed to. Again, this is a remarkably accurate observation, as it is well-known that in many cases of laminitis it will resolve spontaneously.

In the YHLMJ, the basic format remains the same but symptoms and treatment are described in far more detail, and text and its illustration are not confined to a single printed sheet but take as much space as needed. In addition, the YHLMJ tends to describe horse diseases in terms not of pragmatic symptoms - largely (but not exclusively) the case for the Korean text above - but as they relate to the abstract qualities of human medicine as applied to animals. Figure 6 and its companion Figures 7, 8 and 9 are devoted to a horse suffering from 'chill pain'. The illustration is from a very late version of the YHLMJ, a copy of which is included in the Ramey collection. ${ }^{23}$ Significantly, in spite of its late publication date, this edition clearly reflects the original, Ming edition and not later re-workings.

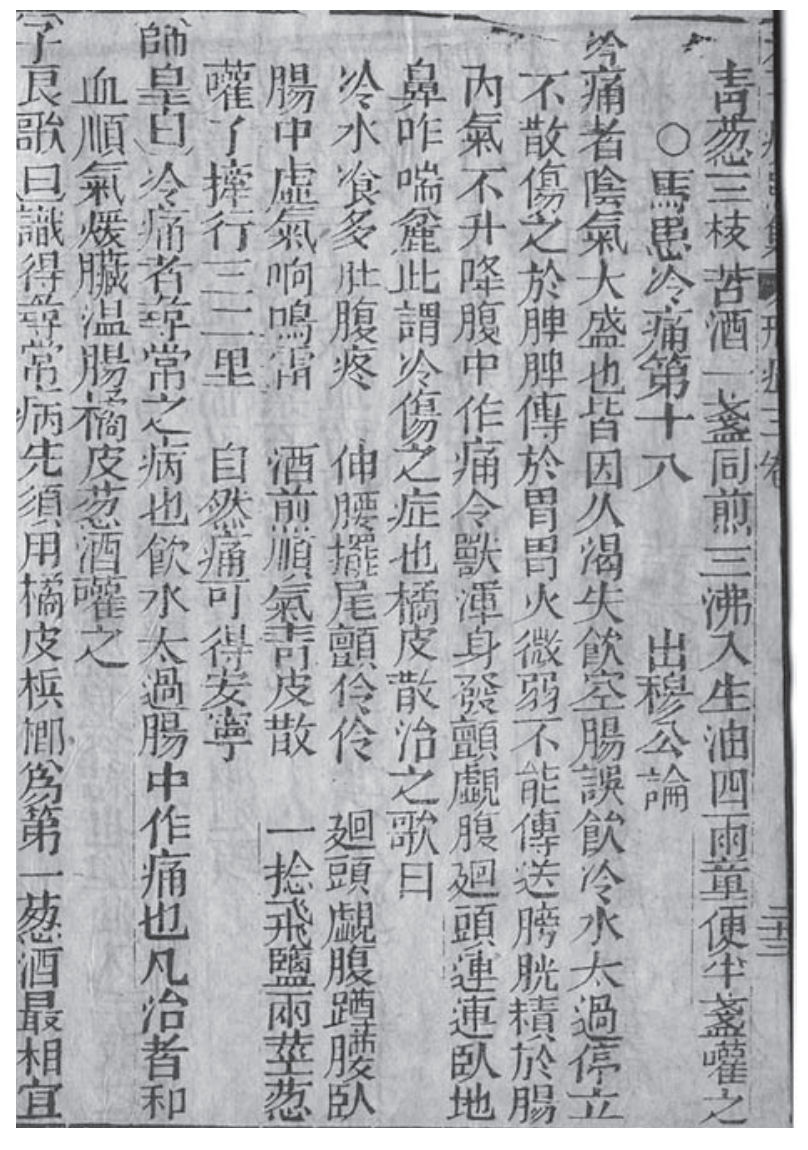

Figure 22.7 Horse suffering from Chill Pain (1)

23 Yuan heng quan tu niu ma tuo jing ji, 3, 23b-25a. 


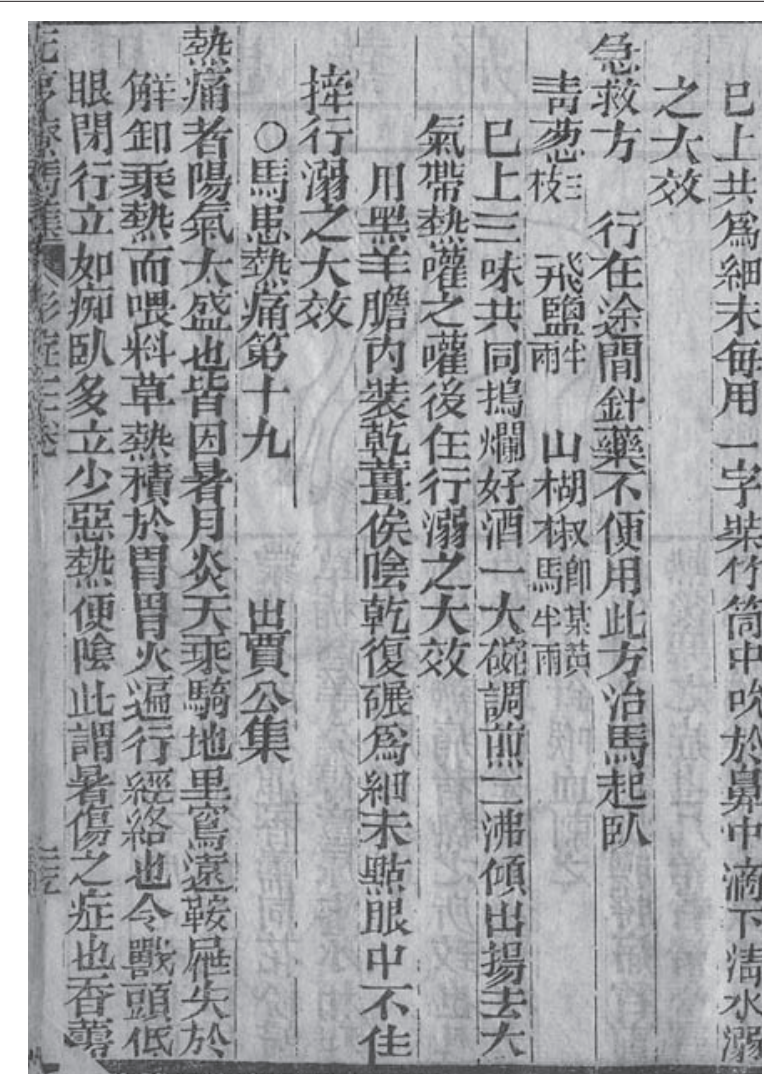

Figure 22.8 Horse suffering from chill pain (4) (continued)

The text passage begins with the title of the condition discussed, number 18 in the series, and a text source for the basic information (giving some indication of the multiple sources of the YHLMJ). Next is a general discussion of the symptom described and its causes, followed by a rhymed summary. This is perhaps the oldest material in the section and is one of the few things that remain unchanged from edition to edition. There follow quotations from authorities including another summary poem, a description of the behaviour of a horse with the condition, pulsing considerations and treatment methods, including bleeding, drenching and herbal application through the nostrils followed by post-treatment options. This section is followed by herbal formulas, varied to suit symptoms, and preparation instructions. The discussion is quite complete and traditional veterinary medicine could add little to what is said here, although some material is rearranged in different editions. ${ }^{24}$

The pattern of the YHLMJ as here became pervasive after Ming times, both in printed texts and in the rich veterinary manuscript tradition, including those manuscripts in the

24 An example of the YHLMJ text of this type, in this case from Guo Huaixi's revised edition is translated in Buell, Ramey and May 2010. It pertains to a surgical operation.

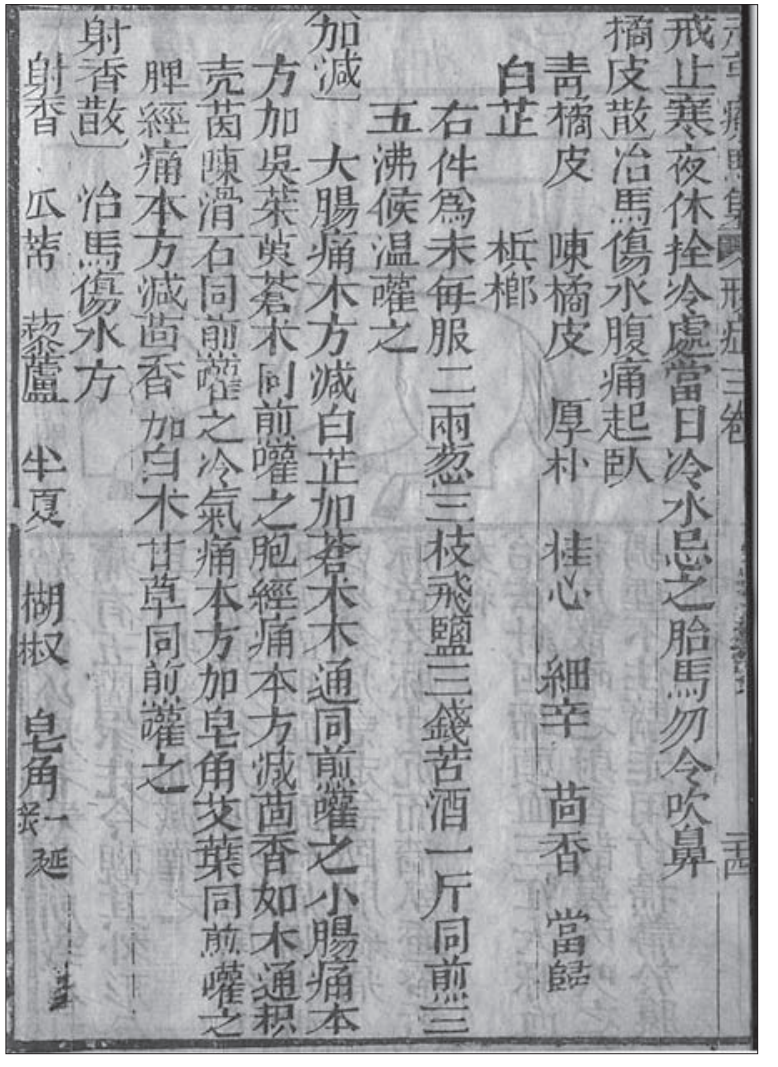

Figure 22.9 Horse suffering from chill pain (3) (continued)

Ramey collection, for example. Figure 10 shows a horse suffering from what seems to be prolapse of the anus, a serious condition, albeit rarely occurring. On the right is a description of symptoms, again, remarkably accurate, and easily recognised by equine veterinary practitioners, followed by a suggested treatment: surgical intervention and herbal treatment. A recipe for the proposed herbal remedy, for irrigation, follows with details about how to prepare and apply the remedy. The only difference between this manuscript, which is possibly late 19th-century, and the YHLMJ is that treatment is more pragmatic and less theory is discussed, although other pages (not this one, however) do include quotations from authorities.

\section{Physiognomy}

In addition to illustrations used to set forth theoretical summaries (e.g., points for cauterisation and what they are used for), and relating to specific diagnostic categories, a popular subject, for horses in particular, was physiognomy. In fact, a large part of manuals such as the YHLMJ is devoted exclusively to horse physiognomy and even texts without extensive illustration go into physiognomy in some detail. 


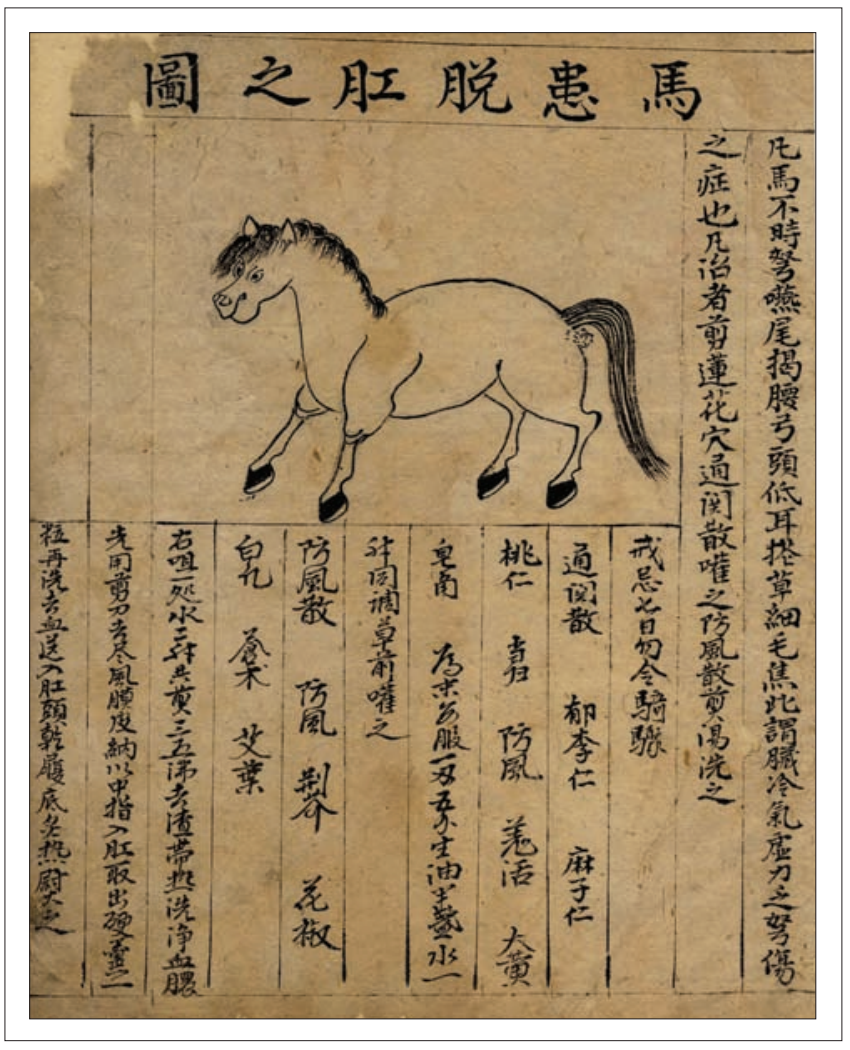

The concern is an ancient one for many reasons. First of all, fine horses are beautiful and owners rejoice in them, in their looks and pedigrees, these sometimes going back many centuries in the Arabian world. Indeed, one study of Bedouin vocabulary listed over a thousand words related to the horse. ${ }^{25}$ These terms include not only ones related to physiognomy, but also epithets and terms used in the commercial exchange of horses. The epithets also provide some insight into traits valued by the Bedouin as well as features that, while not necessarily a negative, were somewhat unusual. One such example is the appearance of a sa'din, which is a double jibhe or shield-like protrusion on a wide-forehead. It is regarded, as indicated by the root of the word, as being auspicious. ${ }^{26}$ These terms can also lead to qualities of a horse deemed favourable such as a mare who can run long distances without becoming winded. Such a mare is known as $q \bar{a} z \bar{a} t$.

And because owners appreciate their horses, they would prefer to predict their qualities and confirm their investments. Secondly, there is the - also age-old - issue of how to choose a good horse, camel, or ox. Above all, physiognomy texts seek to provide a guide to judging horses and other large animals prior to their purchase. This includes determining animal ages. Chinese sources, for example, include teeth diagrams for this purpose. Such

25 Raswan 1945.

26 Raswan 1945, p. 126.
Figure 22.10 Prolapse of the Anus (Ramey A, p. 67). The full text is as follows: [Condition:] Picture of a horse suffering from prolapse of the anus [tuo gang 脫肛]: Whenever a horse unseasonably has an overexertion [crossbow, $n u$ 驽 = 努] throat, raises up its tail, the haunches are curved, the head is lowered, the ears are rolled up, and the grass fine hairs [of the coat] are scorched, then this is called the pathocondition [zheng 症] of chill Qi 氣 of the entrails, and overexertion wound of apparent force. Whenever treating it, one cuts the lotus hole and drenches with Debris Powder Putting-Through-the-Pass and washes with fangfeng [Ledebouriella seseloides] Debris Power decocted into a soup.

It is prohibited to ride the horse energetically for seven days.

Debris Power Putting-Through-the Pass: plum seed, peach seed, Chinese angelica [Angelica sinensis], fangfeng, qianghuo [Notopterygium incisum root], rhubarb [rhizome], Chinese honey-locust [Gleditsia sinensis]. Powder. Each time take 1 qian 錢 [Chinese ounce], 5 fen 分. Produce an oil from the dose. Drench evenly mixed with half a cup of water before [the horse eats] grass.

Fangfeng Debris Powder:fangfeng, jingjie [Schizonepeta tenuifolia herb], Chinese flower pepper, common alum, cangshu [Atracylodes spp.], mugwort [leaf].

Masticate these herbs together. Take two cups of water and decoct together. Bring to a boil three to five times. Remove sediment. Wait until the herbs are cooked. Clean away the pus and blood [from the prolapsed anus]. First use a pair of scissors and remove all the 'wind' membrane skin, Remove so as to be able to insert a finger into the anus and remove the hard covering [?] powder. Wash again and remove the blood. Send [the herbs] into the anus head. When dry, cauterise below the shoe and when ready, apply an iron.

diagrams are a comparative rarity in illustrated veterinary literature found elsewhere. This concern manifests in the Islamic world as well. The concern there was not simple appreciation for the beauty of the horse, but also practical necessity. Although works on furūsiyya or horsemanship existed through medieval Islamic history, a particular emphasis on furūsiyya arose during the period of the Mamluk Sultanate of Egypt and Syria (126o-1517). As a result several of these manuals compiled many ideas and drills for horsemanship as part of the military training of the Mamluks, slaves who were purchased to be trained as soldiers. In addition to listing drills and techniques that were practised in a hippodrome, the furüsiyya manuals also included sections on veterinary care and the qualities of a good horse. This was literature not just for the literati and intellectuals, but for the military. As the Mamluks fought from horseback, the care and knowledge of the horse was crucial to their success. One of the most important furūsiyya manuals is the Kitāb al-siyāsahfì ilm 


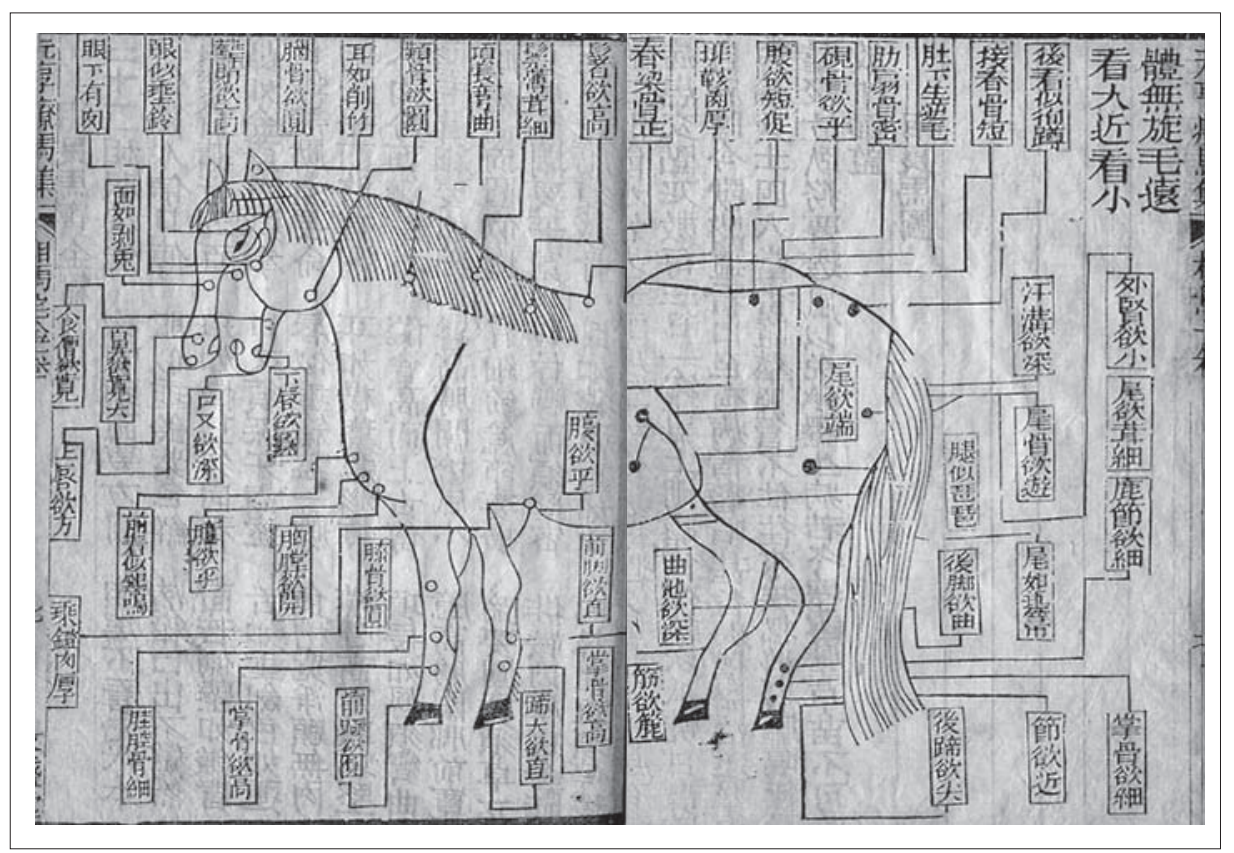

Figure 22.11a, b Physiognomy, detail from the Yuan Heng liaoma ji 元亨療馬集 (YHLMJ), 1608.1, pp. 6b-7a

al-farāsah wa-ashā'ir al-khayl wa amā'irhā (The Book on the Art of Horsemanship and the Knowledge of First-rate Horses and Their Characteristics and Features). Although the text lists the fourth Caliph, 'Alī ibn Abī Tālib (d. 661) as the author, this seems unlikely. Indeed, the copy that exists in the National Library of Medicine was produced in 1830 . As a result, it is uncertain at what point the text came into existence or from where. Nonetheless, it does reinforce the importance of certain qualities such as length and texture of the mane and tail, the shape of the horse's back, neck, and head. The horse should be strong and deep in the shoulder. A curling of hair, such as in the sa'din, anywhere on the body of the horse, except above the nostrils, was deemed a good omen, which could cause a prospective buyer to overlook another fault. Of course, there were also inauspicious marks as well, such as a white mark on the left foreleg accompanied by a white mark on the right hind leg.

Indeed, due to the horse's importance to the Mamluk military, knowledge of horse care and veterinary science was deemed important. This is demonstrated in the Aqrābādhin fí 'ilm tibb al-khayl (Medical Formulary for Horses) which entered the Mamluk sultanate as part of booty taken from a Mamluk assault into the region of Cilicia or Little Armenia in 1266. Sultan Baybars (r. 126o-77) had the work translated from Armenian into Arabic. ${ }^{27}$ In the work, there are sections devoted to the good qualities of a horse, medical care for specific symptoms, and even breeding. An example of a desirable quality according

27 See Dum-Tragut 2005. to the Aqräbādhin is a horse with a thin nose or snout as well as determining the strength or quality of a horse's leg bones. Although it is easy to assume that the ideal animal was an Arabian horse, the Mamluks procured horses from a variety of areas such as Cyrenaica Libya, which produced an entirely different type of horse. Thus while references such as a thin snout may sound similar to an Arabian horse, the Mamluks also sought horses such as the Cyrenican horse, which possessed sturdier legs and was stouter - thus better able to handle rough terrain as well as the weight of the Mamluk in full armour and accoutrements. In short, the contents of these works vary.

In China references to horse physiognomy actually predate any real indications of hippiatrics. Bo Le, for example, was known for his physiognomy before there was any attempt to associate him with medical treatment of horses. ${ }^{28}$ Also predating the now surviving medical literature are the many paintings of famous horses, those attributed to Han Gan 韓幹 (706-83), in particular, although most of the existing paintings attributed to Han are late copies. Under the Mongols, and much of our existing materials seems to date back to the Yuan, China's foreign rulers took a particular interest in the horse, and the Mongolian language, like Arabic is meticulous in its horse descriptions to the point that Mongolian sources of the time spend more time describing what a hero rode than the hero himself, or even his actions. How much Mongolian ideas of horse

28 On Bo Le, see Buell, May and Ramey 2010. See also the relevant sections in Sterckx 2000. 
physiognomy, as expressed in its later manuals, influenced Chinese remains uninvestigated.

Figures 11a and b, part of the same diagram from the YHLMJ (1, 6b-7a), details some principal points on a horse of physiognomic significance with short explanations (e.g., 'one wants the tail bone to be short', 'the ears like sliced bamboo', etc.). ${ }^{29}$ This set of illustrations is then followed by another set of proper characteristics, not supported by an illustration, and then the illustrated detailed guide to horse teeth. Elsewhere in the text there are other illustrations and discussions of more specialised topics related to physiognomy. A connected topic is the determination of the proper days and hours for such activities as bleeding, and cauterisation. This tradition is of great importance for the entire older Chinese veterinary tradition, although mostly forgotten today, particularly by Western practitioners who prefer to see Chinese veterinary medicine as more scientific than it actually is.

\section{Conclusion}

China's rich tradition of veterinary medicine, which becomes a flood during Ming times, is early associated with textual illustrations, including some that clearly once circulated separately. Illustrations, in fact, even when accompanied by explanatory texts, usually have a standalone quality, although some later texts clearly integrate illustrations more or less completely into general discussions of given conditions.

In their essence, traditional Chinese veterinary illustrations are more diagrams than scientifically based technical presentations (compared with medical illustration in late Renaissance texts). They seek to summarise lore and serve as aids to memory rather than seriously present scientific information, but then, half magic, half pragmatic experience, science was never the goal of Chinese horse medicine. Nevertheless, while the treatment options may have little relevance in terms of modern veterinary medicine, the accurate clinical observations indicate that the Chinese were keen observers of the horse.

What is most interesting about them is that the illustrations seem to have roots in early printing (although we have no truly early examples), similarly to Chinese religious broadsides for example; and before such texts were printed, in an illustrated manuscript tradition well

29 For a fuller physiognomy compare, for example, the relevant sections in Guo Huaixi's reworking of the YHLMJ (Guo Huaixi 1732). For a Middle Eastern example of such material, see the horse chart illustrated in Dum-Tragut 2005, p. 101. known from Silk Road finds. The important consideration is that such texts travel easily, witness elements of Chinese popular art that found their way to Iran before and after the Mongol period. ${ }^{30}$ Could this fact explain, given that there were Western equivalents, the apparent easy exchange of veterinary ideas in Eurasia? The traditions become almost identical at both ends of the Silk Road, although, as we demonstrate elsewhere, ${ }^{31}$ the most important ideas went from West to East, and not the reverse.

\section{Bibliography}

\section{Primary Sources}

Bo Le hualuo tugejue 伯樂畫烙圖歌訣 (The Song Secrets of the Diagram of Bo Le's Branding) (BLHLTGJ).

Bo Le zhenjing 伯 樂鍼經 (BLZJ) (Bole's Needling Classic).

Guo Huaixi 郭懷西 1732, Xinke zhushima niu tuojing daquan 新刻注釋 馬牛駝經大全 (Newly Printed and Annotated Horse, Ox, and Camel Classics), reprinted in Zhongguo nongye congkan xumu shouyizhi bu 中國農業叢刊畜牧獸醫之部, Beijing: Nongye chubanshe, 1988, 3-4. Qimin yaoshu 齊民要術 (QMYs), 6th century.

Simu anji ji 司牧安驥集 (SMAJJ) (Collections for Pacifying Stallions when Administering Flocks), 1384.

Xinbian jicheng mayi fang 新編集成馬醫方, (Newly Printed and Collected Recipes for Horse Medicine), 1399.

Yang Shiqiao 楊時喬 (d.16o9), Xinke ma shu 新刻馬書, (Newly Printed Horse Book), 1594.

Yuan Heng liaomaji 元亨療馬集 (YHLMJ) (Yuan and Heng's Collection for Treating Horses), $16 \circ 8$.

Yuan Heng quan tu niu ma tuojingji 元亨全圖療牛馬駝集 (The Yuan and Heng Completely Illustrated Collection for Treating Oxen, Horses and Camels), Sanyi tang zang 三義堂藏, Guangxu 光緒 period, jichou 己丑 year (1889).

\section{Secondary Sources}

Buell, P.D., T. May and D. Ramey 2010, 'Greek and Chinese horse medicine: déjà vu all over again', Sudhoffs Archiv 94.1, 31-56.

2008, 'How did Persian and other western medical knowledge move east, and Chinese west? A look at the role of Rashīd al-Dīn and others', Asian Medicine, Tradition and Modernity 3.2, 278-94.

Cooke, B. (ed.) 2000, Imperial China, The Art of the Horse in Chinese History, Exhibition catalogue, Lexington: Kentucky Horse Park.

Dum-Tragut, J. 2005, Kilikische Heilkunst für Pferde - Das Vermächtnis der Armenier, Hildesheim: Editorial oLMs Verlag.

Epler, D.C. 1980, 'Blood-letting in early Chinese medicine and its relation to the origin of acupuncture', Bulletin of the History of Medicine 54, 337-7.

Franke, H. 1997, 'Zur traditionellen Kamelheilkunde in China', Sudhoffs Archiv 81.1, 84-98.

Kang Myun Hee 姜冕熙 1988 , 'Kankoku jūigaku genshi to Kanpo jūigaku no eikyō' 韓國原始獸醫學と漢方獸醫學の影響, Nihon Jüishigaku Zasshi 日本獸醫學雜誌 (23 March), 34-45.

This topic is vast, see as an introduction Komaroff and Carboni (eds) 2002.

$31 \quad$ See Buell, Ramey and May 2010. 
Komaroff, L. and S. Carboni (eds) 2002, The Legacy of Cinggis-qan, Courtly Art and Culture in Western Asia, 1256-1353, New York: The Metropolitan Museum of Ar/New Haven/London: Yale University Press.

Lo, V. and C. Cullen (eds) 2005, Medieval Chinese Medicine: The Dunhuang Medical Manuscripts, London/New York: RoutledgeCurzon (Needham Research Institute Series).

Ramey, D. and P. Buell 2001, 'Equine medicine in sixth century China: Qimin yaoshu', in Rossdale and Green (eds), 154-61.

Raswan, C.R. 1945, 'Vocabulary of Bedouin words concerning horses', Journal of Near Eastern Studies 4.2, 97-129.

Rossdale, P. and R. Green 2001 (eds), Guardians of the Horse, II, Newmarket: Romney Publications.

Sterckx, R. 2000, The Animal and the Daemon in Early China, Albany:
SUNY Press.

Stork, M. 1971, 'Lehrschemata in europäischen Tierheilkundebüchern des 16. bis 18. Jahrhunderts: Lassrösslein - Krankheitsnamenpferd - Fehlerpferd', Zentralblatt für Veterinärmedizin, Reihe A, vol. 18:8, 661-707.

von den Driesch, A. and J. Peters 2003, Geschichte der Tiermedizin, 50ooJahre Tierheilkunde, 2nd edn, Stuttgart/New York: Schattauer.

Wang Shishun 王世舜 et al. (eds) 1983, Zhuangziyizhu 莊子譯注 (Jinan: Shandong jiaoyu chubanshe.

Xie Guihua (tr. V. Lo) 2005, 'Han bamboo and wooden medical records discovered in military sites from the northwestern frontier regions', in Lo and Cullen (eds), 78-106.

Zhou Jiezheng 鄒介正 1960, 'Tangdai di zhenlao shu' 唐代的針烙術, Nongshiyanjiujikan 3, 159-74. 